\title{
Thermochemically Stable Liquid-Crystalline Gold(I) Complexes Showing Enhanced Room Temperature Phosphorescence
}

\author{
Yuki Kuroda ${ }^{1}$ (), Shin-ya Nakamura ${ }^{1}$, Katam Srinivas ${ }^{2}$, Arruri Sathyanarayana ${ }^{1}$, \\ Ganesan Prabusankar ${ }^{2}$ (D) Kyohei Hisano ${ }^{1}$ (D) and Osamu Tsutsumi ${ }^{1, *(D)}$ \\ 1 Department of Applied Chemistry, Ritsumeikan University, 1-1-1 Nojihigashi, Kusatsu 525-8577, Japan; \\ sc0050ir@ed.ritsumei.ac.jp (Y.K.); sc0034vr@gmail.com (S.N.); sathya@fc.ritsumei.ac.jp (A.S.); \\ hisano@fc.ritsumei.ac.jp (K.H.) \\ 2 Department of Chemistry, Indian Institute of Technology, Kandi, Sangareddy TS 502285, India; \\ cy13p0004@iith.ac.in (K.S.); prabu@iith.ac.in (G.P.) \\ * Correspondence: tsutsumi@sk.ritsumei.ac.jp; Tel.: +81-77-561-5966
}

Received: 29 March 2019; Accepted: 26 April 2019; Published: 27 April 2019

\begin{abstract}
Gold(I) complexes are some of the most attractive materials for generating aggregation-induced emission (AIE), enabling the realization of novel light-emitting applications such as chemo-sensors, bio-sensors, cell imaging, and organic light-emitting diodes (OLEDs). In this study, we propose a rational design of luminescent gold complexes to achieve both high thermochemical stability and intense room temperature phosphorescence, which are desirable features in practical luminescent applications. Here, a series of gold(I) complexes with ligands of $N$-heterocyclic carbene (NHC) derivatives and/or acetylide were synthesized. Detailed characterization revealed that the incorporation of NHC ligands could increase the molecular thermochemical stability, as the decomposition temperature was increased to $\sim 300{ }^{\circ} \mathrm{C}$. We demonstrate that incorporation of both NHC and acetylide ligands enables us to generate gold(I) complexes exhibiting both high thermochemical stability and high room-temperature phosphorescence quantum yield $(>40 \%)$ under ambient conditions. Furthermore, we modified the length of alkoxy chains at ligands, and succeeded in synthesizing a liquid crystalline gold(I) complex while maintaining the relatively high thermochemical stability and quantum yield.
\end{abstract}

Keywords: aggregation-induced emission; room-temperature phosphorescence; gold(I) complex; $\mathrm{N}$-heterocyclic carbene; acetylide; liquid crystal

\section{Introduction}

Nanolights, consisting of organic or inorganic compounds with a size of a few nanometers, enable the emission of bright light, and are attracting growing interest in the fields of bio-imaging, sensing, energy harvesting, and displays [1]. Quantum dots as inorganic semiconductors continue to be at the forefront of nanolight development due to their commercial availability and facile fabrication to obtain a desired color [2]. However, the toxicity of the components used to prepare quantum dots (e.g., cadmium) limits their potential applications. To overcome this issue, various approaches and designs have been proposed [3,4]. One intriguing alternative is the use of organic materials, but a significant scientific challenge remains; although typical organic materials can show strong emission when dispersed, such as in solution, aggregation and condensation of the molecules quench this emission due to intramolecular interactions in a process known as aggregation-caused quenching. Pioneering research to address this challenge was performed in 2001 by the group of Tang [5-7], in which they proposed the concept of designing molecules with unique twisted shapes, such as tetraphenylethene, which restrict intramolecular interactions; these molecules strongly emit light in 
the aggregate phase. This phenomenon is referred to as aggregation-induced emission (AIE). Inspired by this pioneering research, numerous AIE materials have been investigated for applications such as chemo-sensors, bio-sensors, cell imaging, and organic light-emitting diodes (OLEDs). More recently, liquid crystalline AIE molecules have attracted much attention. Liquid crystals intrinsically have both the self-organized ordered structures and the tunability of structures by using external stimuli such as light, heat, electricity, etc. Thus, liquid crystalline AIE molecules provide us with a pathway for generating highly efficient, stimuli-responsive photoluminescent materials.

Among advanced liquid crystalline AIE molecules, light emissive metallomesogen, that is the liquid crystals containing metal centers (e.g., In, $\mathrm{Ru}, \mathrm{Re}, \mathrm{Cu}, \mathrm{Ni}, \mathrm{Pd}, \mathrm{Pt}, \mathrm{Ag}, \mathrm{Au}$, etc.), is a promising luminescent material [8-12]. This is because metallomesogens emit phosphorescence, which theoretically has the potential to yield bright light with $100 \%$ quantum yield. In particular, the $\mathrm{d}^{10}$ transition-metallomesogens, for example, containing $\mathrm{Cu}(\mathrm{I}), \mathrm{Ag}(\mathrm{I}), \mathrm{Au}(\mathrm{I})$, are an attractive choice for liquid crystalline AIE molecules since such metallomesogens hardly show any emission when dispersed but strongly emit phosphoresce in aggregates owing to metal-metal interactions. Based on this idea, we have previously synthesized a family of gold(I) complexes [13-23]. Gold complexes enable $\mathrm{Au}-\mathrm{Au}$ (aurophilic) interactions in an aggregate state where the gold atoms approach a range of 2.8 to $3.6 \AA$ [24]. Many researchers have reported that aurophilic interactions generate strong luminescence from aggregated complexes; thus, gold complexes are well known to be AIE active materials. Our design concept relies on the reduction of steric hindrance around the gold(I) ions to promote aurophilic interactions. For example, we have designed luminescent trinuclear gold complexes based on this concept. We reported a gold(I) complex exhibiting crystal polymorphism that we were able to reversibly tune to provide luminescence from purple to red by crystalline-to-crystalline phase transitions [20]. We also developed a mononuclear rod-like gold-acetylide complex, $\mathbf{1}$, as shown in Figure 1, which displayed extremely intense phosphorescence (i.e., the quantum yield $(\Phi)$ was 0.5 ) from crystals at room temperature, and possessed liquid crystallinity [23].

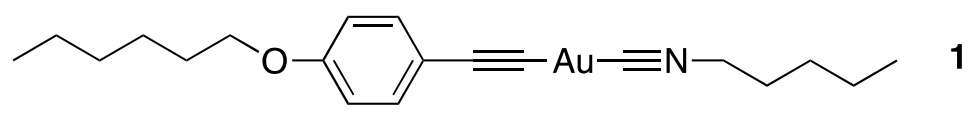<smiles>[R]c1cc2c(cc1[R])N(C)C([Ge]Cl)N2C</smiles>

2a: $\mathrm{R}=\mathrm{H}$
2b: $\mathrm{R}=\mathrm{O}-n-\mathrm{C}_{6} \mathrm{H}_{13}$

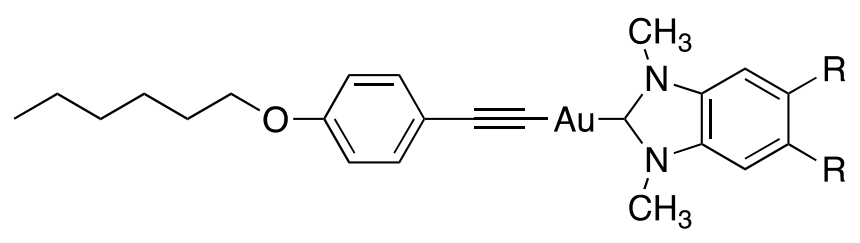

3a: $\mathrm{R}=\mathrm{H}$

3b: $\mathrm{R}=\mathrm{O}-n-\mathrm{C}_{6} \mathrm{H}_{13}$

Figure 1. Molecular structure of gold complexes used in this study.

Recently, we developed gold complexes $\mathbf{2 a}$ and $\mathbf{2} \mathbf{b}$ with $\mathrm{N}$-heterocyclic carbene (NHC) ligands, which have extraordinarily strong $\sigma$-donor properties that can facilitate stable metal-organic bonds. The gold(I) NHC complexes exhibited very high thermochemical stability; decomposition temperatures were higher than $280^{\circ} \mathrm{C}$ [14]. In addition, complex 2a displayed mechanochromism, in which the luminescence significantly changed from orange to deep blue upon grinding due to changes in the crystal structure. 
Inspired by our previous research, we wanted to investigate whether highly stable gold(I) complexes exhibiting intense room-temperature phosphorescence could be obtained by combining the molecular units of complexes $\mathbf{1}$ and $\mathbf{2}$. In this work, therefore, we designed and synthesized a series of complexes containing both acetylide and NHC ligands as complexes $\mathbf{3 a}$ and $\mathbf{3 b}$, see Figure 1 . Here, we discuss the thermodynamic behavior and photophysical properties of the new complex 3 by comparing them with the previously reported complexes $\mathbf{1}$ and $\mathbf{2}$. We found that both thermochemical stability and luminescence efficiency can be enhanced by combining acetylide and NHC ligands in gold(I) complexes $\mathbf{3}$, which is based on our earlier investigations of complexes $\mathbf{1}$ and $\mathbf{2}$. Furthermore, we found that the modification of the length of alkoxy chains at ligands greatly affected the liquid crystallinity of the resultant complexes, and succeeded in synthesizing a metallomesogenic AIE material.

\section{Materials and Methods}

\subsection{Materials}

The synthesis and purification of complexes 1 and 2 have already been reported [14,23-26]. New complexes 3 were synthesized by a facile one-step procedure from complexes 2 and 1-ethynyl4-hexyloxybenzene, as shown in Scheme 1. All solvents and reagents were reagent grade and commercially available, and they were used without further purification unless otherwise stated. ${ }^{1} \mathrm{H}$ NMR spectra were recorded in $\mathrm{CDCl}_{3}$ at $400 \mathrm{MHz}$ using a ECS-400 spectrometer (JEOL, Tokyo, Japan). Chemical shifts are reported in parts per million (ppm) using the residual proton in the NMR solvent as an internal reference. IR spectra were obtained using the $\mathrm{KBr}$ disk method with an FT/IR-610 spectrometer (JASCO, Tokyo, Japan), and all spectra are reported in wavenumbers $\left(\mathrm{cm}^{-1}\right)$. HRMS were recorded with a JMS-700 spectrometer (JEOL, Tokyo, Japan). Elemental analyses for C, $\mathrm{H}$, and $\mathrm{N}$ were conducted with a MICRO CORDER JM10 analyzer (J-SCIENCE, Tokyo, Japan).

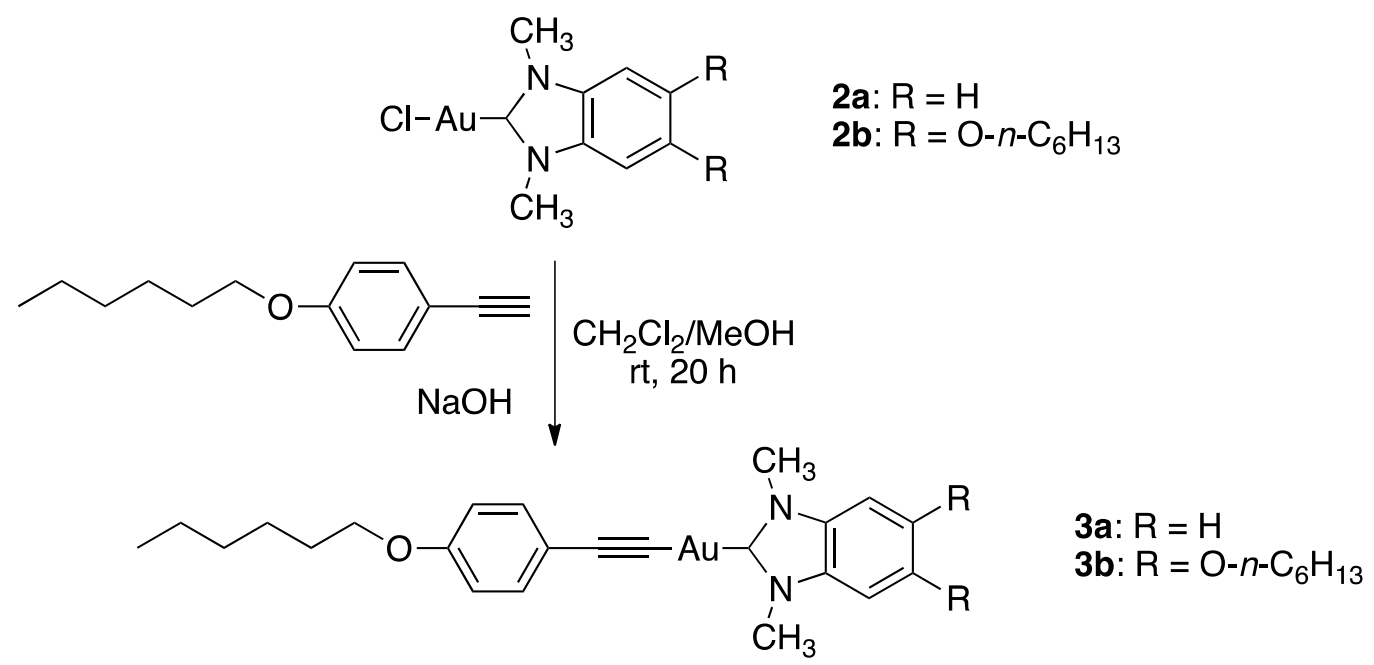

Scheme 1. Synthetic route to gold complexes $3 \mathbf{a}$ and $3 \mathbf{b}$.

\subsection{Synthesis of Au Complex $3 a$}

Chloro(1,3-dimethylbenzimidazolin-2-ylidene)gold(I), 2a, (64 mg, $9.2 \mathrm{mmol}$ ), 1-ethynyl4-hexyloxybenzene $(0.10 \mathrm{~g}, 0.51 \mathrm{mmol})$, and sodium hydroxide $(23 \mathrm{mg}, 0.56 \mathrm{mmol})$ were added to $\mathrm{CH}_{2} \mathrm{Cl}_{2}(20 \mathrm{~mL})$ and methanol $(10 \mathrm{~mL})$, and the mixture was stirred at room temperature for $20 \mathrm{~h}$. The mixture was extracted with $\mathrm{CH}_{2} \mathrm{Cl}_{2}$, then washed with water and brine. The organic layer was dried with anhydrous sodium sulfate and was concentrated by evaporation. The crude product was purified by recrystallization from a mixed solvent system of $\mathrm{CH}_{2} \mathrm{Cl}_{2}$ and hexane to afford $\mathbf{3 a}$ as colorless needles (80\%, $74 \mathrm{mg}, 0.14 \mathrm{mmol})$. m.p.: $189^{\circ} \mathrm{C} .{ }^{1} \mathrm{H}$ NMR $\left(\mathrm{CDCl}_{3}, \delta\right): 7.47-7.44(\mathrm{~m}, 6 \mathrm{H} ; 4,5,6,7-\mathrm{H}$ of benzimidazole, 2,6- $\mathrm{H}$ in phenyl), $6.77\left(\mathrm{dd}, \mathrm{J}=6.8,2.3 \mathrm{~Hz} ; 2 \mathrm{H} ; 3,5-\mathrm{H}\right.$ of phenyl), $4.06\left(\mathrm{~s}, 6 \mathrm{H} ;\left(\mathrm{NCH}_{3}\right)_{2}\right)$, 
$3.93\left(\mathrm{t}, \mathrm{J}=6.6 \mathrm{~Hz} ; 2 \mathrm{H} ; \mathrm{OCH}_{2}\right.$ ), 1.76 (quin, $\mathrm{J}=7.0 \mathrm{~Hz} ; 2 \mathrm{H} ; \mathrm{OCH}_{2} \mathrm{CH}_{2}$ ), 1.44 (quin, $\mathrm{J}=7.2 \mathrm{~Hz} ; 2 \mathrm{H}$;

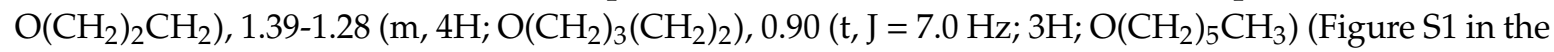
supplementary materials). IR (KBr, v): 3033, 2937, 2856, 1604, 1505, 1241, $740 \mathrm{~cm}^{-1}$. HRMS (FAB) m/z: $[\mathrm{M}+\mathrm{Na}]^{+}$calcd. for $\mathrm{C}_{23} \mathrm{H}_{27} \mathrm{AuN}_{2} \mathrm{ONa}$, 567.1674; found, 567.1687. Anal. calcd. for $\mathrm{C}_{23} \mathrm{H}_{27} \mathrm{AuN}_{2} \mathrm{O}: \mathrm{C}$, 50.74; H, 5.00; N, 5.15; O, 2.94; Au,36.17; found: C, 50.68; H, 4.73; N, 5.23; O, 3.42; ash, 35.94.

\subsection{Synthesis of Au Complex $3 b$}

Using the same procedure as described for $\mathbf{3} \mathbf{a}$, complex $\mathbf{3} \mathbf{b}$ was obtained from the corresponding complex (2b) as colorless needles in $86 \%$ yield. m.p.: $207^{\circ} \mathrm{C} .{ }^{1} \mathrm{H}$ NMR $\left(\mathrm{CDCl}_{3}, \delta\right): 7.44(\mathrm{dd}, \mathrm{J}=6.8$, $2.3 \mathrm{~Hz} ; 2 \mathrm{H} ; 2,6-\mathrm{H}$ of phenyl), 6.85 (s, 2H; 4,7-H of benzimidazole), 6.77 (dd, J = 6.8, $2.3 \mathrm{~Hz} ; 2 \mathrm{H} ; 3,5-\mathrm{H}$ of phenyl), $4.03\left(\mathrm{t}, \mathrm{J}=6.6 \mathrm{~Hz} ; 4 \mathrm{H}\right.$; benzimidazole- $\left.\left(\mathrm{OCH}_{2}\right)_{2}\right), 3.98\left(\mathrm{~s}, 6 \mathrm{H} ;\left(\mathrm{NCH}_{3}\right)_{2}\right), 3.93(\mathrm{t}, \mathrm{J}=6.6 \mathrm{~Hz}$; $2 \mathrm{H}$; phenyl-OCH${ }_{2}$ ), 1.87 (quin, $\mathrm{J}=7.0 \mathrm{~Hz} ; 4 \mathrm{H}$; benzimidazole- $\left.\left(\mathrm{OCH}_{2} \mathrm{CH}_{2}\right)_{2}\right), 1.76$ (quin, $\mathrm{J}=7.0 \mathrm{~Hz}$; $2 \mathrm{H}$; phenyl- $\left.\mathrm{OCH}_{2} \mathrm{CH}_{2}\right), 1.51$ (quin, $\mathrm{J}=7.4 \mathrm{~Hz} ; 4 \mathrm{H}$; benzimidazole- $\left.\left(\mathrm{O}_{(}\left(\mathrm{CH}_{2}\right)_{2} \mathrm{CH}_{2}\right)_{2}\right), 1.44(\mathrm{~m}, 2 \mathrm{H}$; phenyl-O $\left.\left(\mathrm{CH}_{2}\right)_{2} \mathrm{CH}_{2}\right), 1.39-1.29\left(\mathrm{~m}, 12 \mathrm{H}\right.$; benzimidazole- $\left(\mathrm{O}\left(\mathrm{CH}_{2}\right)_{3}\left(\mathrm{CH}_{2}\right)_{2}\right)_{2}$, phenyl-O $\left.\left(\mathrm{CH}_{2}\right)_{3}\left(\mathrm{CH}_{2}\right)_{2}\right)$, 0.91 (m, 9H; benzimidazole- $\left(\mathrm{O}\left(\mathrm{CH}_{2}\right)_{5} \mathrm{CH}_{3}\right)_{2}$, phenyl- $\left.\mathrm{O}\left(\mathrm{CH}_{2}\right)_{5} \mathrm{CH}_{3}\right)$ (Figure $\left.\mathrm{S} 2\right)$. IR $(\mathrm{KBr}, \mathrm{v})$ : 3053, 2927, 2869, 1603, 1504, 1462, $1264 \mathrm{~cm}^{-1}$. HRMS (FAB) m/z: [M] ${ }^{+}$calcd. for $\mathrm{C}_{35} \mathrm{H}_{51} \mathrm{AuN}_{2} \mathrm{O}_{3}, 744.3572$; found, 744.3565. Anal. calcd. for $\mathrm{C}_{35} \mathrm{H}_{51} \mathrm{AuN}_{2} \mathrm{O}_{3}$ : $\mathrm{C}, 56.44 ; \mathrm{H}, 6.90 ; \mathrm{N}, 3.76 ; \mathrm{O}, 6.44 ; \mathrm{Au}, 26.46$; found: $\mathrm{C}, 54.52$; $\mathrm{H}, 6.42 ; \mathrm{N}, 3.74 ; \mathrm{O}, 6.77$; ash, 28.55 .

\subsection{Single Crystal X-ray Structure Analysis}

Single crystals of gold(I) complexes 3 were obtained by slow evaporation from a mixed solvent system (1:1 hexane/dichloromethane (v/v)). Each crystal was mounted on a glass fiber and the omega scanning technique was used to collect the reflection data using a Bruker D8 goniometer with monochromatic Mo K $\alpha$ radiation $(\lambda=0.71075 \AA)$. To investigate the actual crystal structure of in-use materials, the measurements were performed at ambient temperature $(296 \mathrm{~K})$. The initial structure of each unit cell was determined using a direct method in APEX3. The structural models were refined using a full-matrix least squares method in SHELXL-2014/6 [27,28]. All calculations were performed using SHELXL programs. The crystal data for complexes $\mathbf{3 a}$ and $\mathbf{3 b}$ are summarized in Table S1, see Supporting Information, and have been deposited in the Cambridge Crystallographic Data Centre (CCDC) database (CCDC: 1876552 for complex 3a, 1876306 for complex 3b).

\subsection{Thermochemical and Photoluminescence Properties}

The thermochemical stabilities of Au complexes were analyzed with a thermogravimetric/ differential thermal analyzer (TG/DTA; DTG-60AH, Shimadzu, Kyoto, Japan) at a heating rate of $5.0^{\circ} \mathrm{C} \mathrm{min}-1$. The phase transition properties of Au complexes were observed with a polarized optical microscope (POM; BX51, Olympus, Tokyo, Japan) equipped with a heating/cooling stage (HCS302, Instec). The thermodynamic parameters were determined using differential scanning calorimetry (DSC) (X-DSC7000, SII) at heating and cooling rates of $5.0^{\circ} \mathrm{C} \mathrm{min}^{-1}$ for complexes 1, 2a, and 3a,

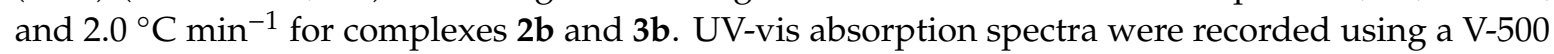
spectrophotometer (JASCO, Tokyo, Japan). Steady-state photoluminescence spectra were obtained using a F-7000 fluorescence spectrophotometer (Hitachi, Tokyo, Japan). Photoluminescence quantum yields were measured using a calibrated integrating sphere system (Hitachi). Photoluminescence lifetimes were determined using a Nd:YAG laser (Continuum, Minilite II; $\lambda=355 \mathrm{~nm}$, FWHM $=4 \mathrm{~ns}$, repetition rate $=10 \mathrm{~Hz}$ ) as the excitation source, with decay profiles recorded using a streak camera (C7700, Hamamatsu Photonics, Hamamatsu, Japan). 


\section{Results and Discussion}

\subsection{Synthesis and Structural Characterization of Complexes}

Au complexes 3 were synthesized by referring to previous reports [14,23]. Complex 2a was prepared from commercially available 1,2-diaminobenzene derivative in two steps; complex $2 \mathbf{b}$ was also obtained similarly from the corresponding 1,2-diaminobenzene derivative, which was synthesized according to the previous report [14] in two steps. The complexes 2 were then treated with 1-ethynyl-4-hexyloxybenzene to yield the desired complexes 3 as crystals after recrystallization. The synthesis and characterization of complexes 1 and $\mathbf{2}$ have already been reported [14,23]; the same spectral data were obtained here. New complexes 3 were fully characterized by ${ }^{1} \mathrm{H}$ NMR spectroscopy, IR spectroscopy, HRMS, elemental analysis, and X-ray crystallography. The analytical data for new complexes 3 are given in Sections 2.2 and 2.3. The data confirm that the desired complexes were obtained at considerably high purity.

Single crystals of all complexes were obtained by slow evaporation from a mixed solvent system (1:1 hexane/dichloromethane (v/v)). The molecular structures and crystal structures of the complexes obtained using single-crystal X-ray structural analysis are shown in Figure 2 and Figure S3 and the crystallographic data are listed in Table S1. To analyze structure-property relationships, the interatomic distances between neighboring $\mathrm{Au}$ atoms and $\mathrm{Au}-\mathrm{C}_{\mathrm{NHC}}$ bond lengths are summarized in Table 1. The sum of the van der Waals radii of two Au atoms is $3.6 \AA$ [24,29]. Any intermolecular $\mathrm{Au}-\mathrm{Au}$ distance $\leq 3.6 \AA$ indicates the existence of aurophilic interactions; thus it can be concluded that aurophilic interactions occur for acetylide-containing complex $\mathbf{1}$ and NHC-containing complexes without alkoxy substituents on the phenyl ring of the benzimidazole, viz. 2a and 3a. Incorporation of two flexible chains on the NHC ligand increases steric hindrance around the Au atoms, and, therefore, $\mathbf{2 b}$ and $\mathbf{3 b}$ do not exhibit aurophilic interactions [30].

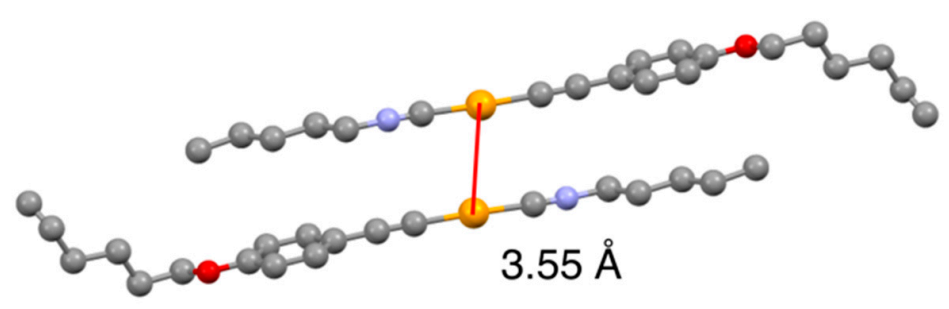

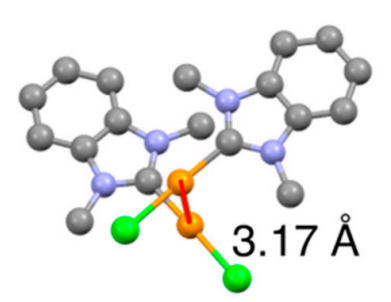

2a

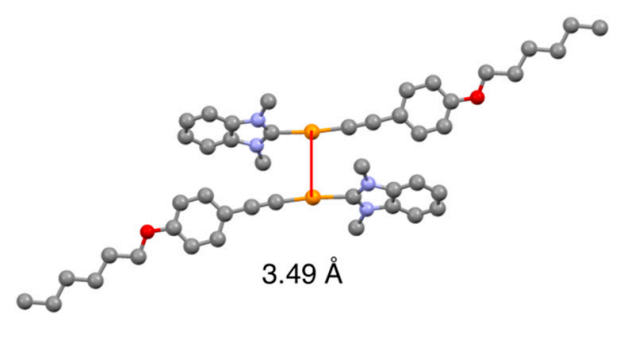

$3 a$

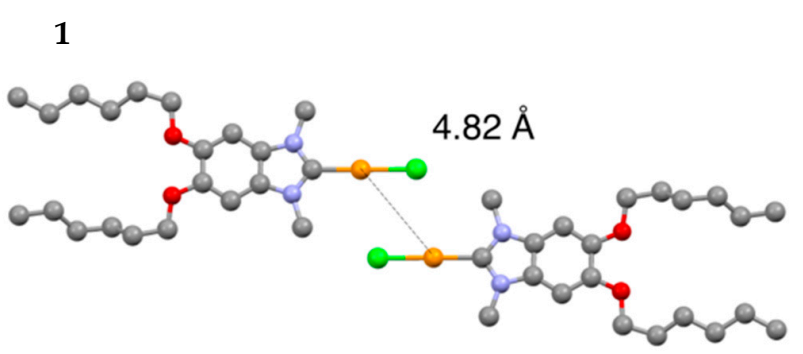

$2 b$

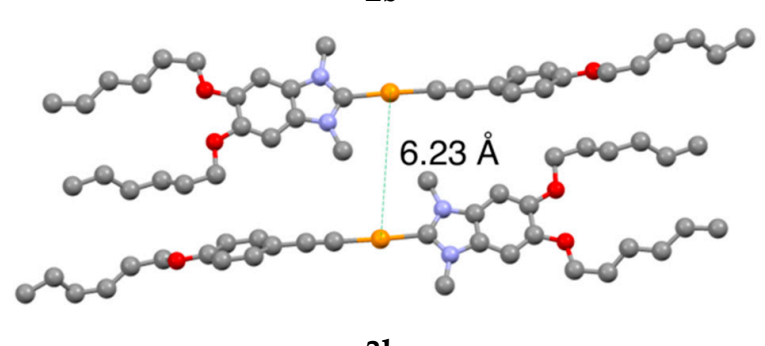

$3 b$

Figure 2. Crystal structure of gold complexes. Color legend: gray, C; red, O; purple, N; green, Cl; orange, Au. Intermolecular $\mathrm{Au}-\mathrm{Au}$ interactions are indicated with a red line. 
Table 1. Intermolecular distance between neighboring $\mathrm{Au}$ atoms in the crystal and thermal decomposition temperature $\left(T_{\mathrm{dec}}\right)$ of Au complexes.

\begin{tabular}{cccc}
\hline Complex & Intermolecular $\mathbf{A u}-\mathbf{A u}$ Distance $(\AA)$ & Bond Length of $\mathbf{A u}-\mathbf{C}_{\mathbf{N H C}}(\AA)$ & $\mathbf{T}_{\mathbf{d e c}}\left({ }^{\circ} \mathbf{C}\right)$ \\
\hline $\mathbf{1}$ & 3.55 & - & 159 \\
$\mathbf{2 a}$ & 3.17 & 1.98 & 298 \\
$\mathbf{2 b}$ & 4.82 & 2.00 & 282 \\
$\mathbf{3 a}$ & 3.49 & 2.10 & 278 \\
$\mathbf{3 b}$ & 6.23 & 2.01 & 291 \\
\hline
\end{tabular}

\subsection{Thermal Properties}

To assess the thermochemical stability of the gold complexes, we carried out TG/DTA measurements from 25 to $600{ }^{\circ} \mathrm{C}$ at a heating rate of $5.0^{\circ} \mathrm{C} \mathrm{min}-1$ in air. Here, the thermal decomposition temperature $\left(\mathrm{T}_{\mathrm{dec}}\right)$ is defined as the temperature at which $5 \%$ loss of mass occurs during heating. The TG/DTA thermograms obtained for complexes 3 are shown in Figure 3, and $T_{\text {dec }}$ for each complex is listed in Table 1 . The $\mathrm{T}_{\mathrm{dec}}$ for complexes $\mathbf{3 a}$ and $\mathbf{3 b}$ were found to be 278 and $291{ }^{\circ} \mathrm{C}$, respectively; these data confirm that both complexes 3 have nearly the same $T_{\text {dec }}$ as 2 , and that they are more thermally resistant than complex $\mathbf{1}$.

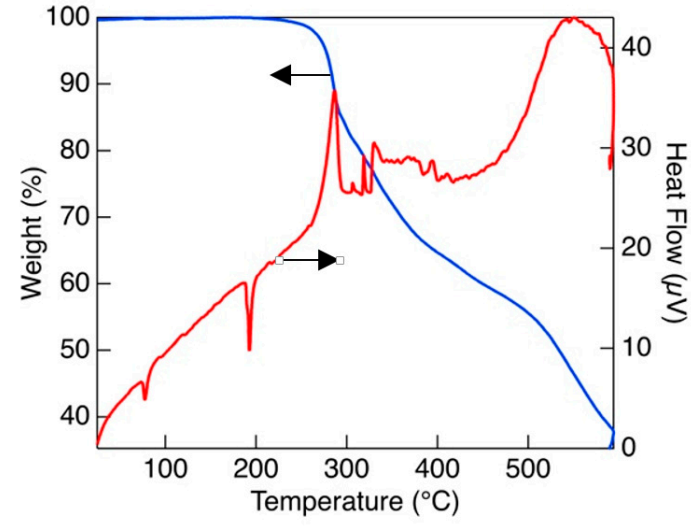

(a)

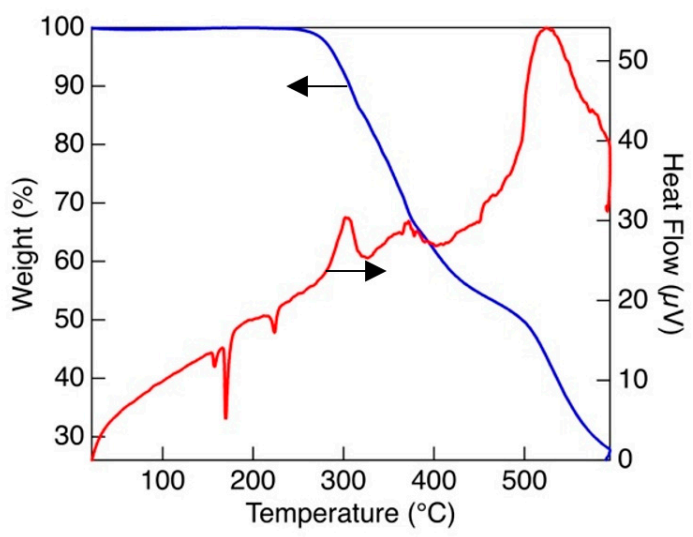

(b)

Figure 3. Thermogravimetric/differential thermal analyzer (TG/DTA) thermograms of complexes 3 in air (heating rate $=5.0^{\circ} \mathrm{C} \mathrm{min}-1$ ): (a) $3 \mathbf{a}$ and (b) $3 \mathbf{b}$.

Comparing the TGA thermograms of all the complexes provides useful information about the thermal decomposition behavior (Figure 3 and Figure S4). As reported previously, complex 1, having both isocyanide and acetylide ligands, showed $18 \%$ mass loss at its $\mathrm{T}_{\mathrm{dec}}\left(159^{\circ} \mathrm{C}\right)$, which corresponds to the mass percentage of the isocyanide ligand $(20 \%)$; therefore, it was concluded that bond cleavage between the isocyanide ligand and $\mathrm{Au}$ atom is the first step of thermal decomposition for complex 1 [23]. At $380^{\circ} \mathrm{C}$, the second mass loss of complex 1 occurred gradually until the residual mass reached $41 \%$, which corresponds to the mass percentage of the Au atom, suggesting that the acetylide ligand was cleaved at this temperature as the second thermal decomposition process and that metallic $\mathrm{Au}(0)$ finally remains. On the other hand, complex 2 a exhibits a $40 \%$ mass loss at its $\mathrm{T}_{\mathrm{dec}}\left(298^{\circ} \mathrm{C}\right)$, which corresponds to the mass percentage of the NHC ligand, and then the gradual second mass loss occurs until the residual mass is that of $\mathrm{Au}$ [14]. The same behavior was observed for $\mathbf{2} \mathbf{b}$. The results obtained from complexes 1 and $\mathbf{2}$ suggest that both the NHC ligand and phenyl acetylide ligand form a stable bond with the $\mathrm{Au}(\mathrm{I})$ ion, and that those bonds are cleaved at $\sim 30{ }^{\circ} \mathrm{C}$ or higher.

In the case of $3 \mathbf{a}$, the $\mathrm{T}_{\mathrm{dec}}$ was observed at $278^{\circ} \mathrm{C}$ with the drastic mass loss of $33 \%$ and remained until $\sim 380^{\circ} \mathrm{C}$, whereby the loss at this first decomposition stage roughly matches the mass percentage of the NHC ligand (27\%). The second mass loss of $30 \%$ took place gradually from $380{ }^{\circ} \mathrm{C}$ until the 
residual mass reached $38 \%$ at $600{ }^{\circ} \mathrm{C}$. The final residual weight effectively matched with the mass percentage of $\mathrm{Au}$ atom (36\%). Similar thermochemical behavior was observed for $\mathbf{3 b}$. By analogy with complexes 1 and 2, it can be concluded that the first mass loss at $\sim 290^{\circ} \mathrm{C}$ is attributable to elimination of the NHC ligand from the complex, and the second mass loss process is assigned to the liberation of the acetylide ligand. Namely, substitution of the isocyanide ligand in complex $\mathbf{1}$ by the NHC ligands enhances the thermochemical stability of $\mathrm{Au}(\mathrm{I})$ complexes.

From the aforementioned discussion, the general relationship between the chemical structure and thermochemical stability of NHC Au(I) complexes can be identified. The thermal decomposition of the complexes containing NHC ligands is initiated from the cleavage of the $\mathrm{Au}-\mathrm{C}_{\mathrm{NHC}}$ bond; thus, we can hypothesize that the thermochemical stability of those complexes is affected by the $\mathrm{Au}-\mathrm{C}_{\mathrm{NHC}}$ bond strength. In Table 1 , the $\mathrm{Au}-\mathrm{C}_{\mathrm{NHC}}$ bond lengths are summarized and juxtaposed against $\mathrm{T}_{\mathrm{dec}}$. Comparing the data of complexes $\mathbf{2}$ and 3, it can be seen that there is a relationship between the bond length and thermochemical stability. In general, the shorter the bond length, the higher the stability, and, therefore, the larger the bond dissociation energy is. Accordingly, it can be concluded that the $\mathrm{Au}-\mathrm{C}_{\mathrm{NHC}}$ bond length determines the thermochemical stability of the $\mathrm{NHC} \mathrm{Au}(\mathrm{I})$ complexes of this type.

The thermodynamic properties of the Au complexes were studied using differential scanning calorimetry (DSC) and polarized optical microscopy (POM). The phase transition behaviors are summarized in Table 2. The liquid crystal (LC) phase was identified as nematic $(\mathrm{N})$ or smectic $(\mathrm{Sm})$ by POM, based on the optical textures observed, see Figure 4. Complex 1 exhibited an enantiotropic $\mathrm{N}$ phase [23]; however, complexes 2 did not show any LC phases at any temperature. Generally, rod-like molecules with a high aspect ratio tend to exhibit the LC phase. We reported that molecules of complex 1 formed dimers oriented anti-parallel via the $\mathrm{Au}-\mathrm{Au}$ interaction, and that these act as unit mesogens possessing a high aspect ratio [23]. In the case of complex $\mathbf{2} \mathbf{b}$, no LC phase was observed due to the wider benzimidazole moiety relative to the phenylacetylene moiety of complex $\mathbf{1}$, which results in an aspect ratio of the mesogenic core that is insufficient to form LC phases in both its monomeric and dimeric forms.

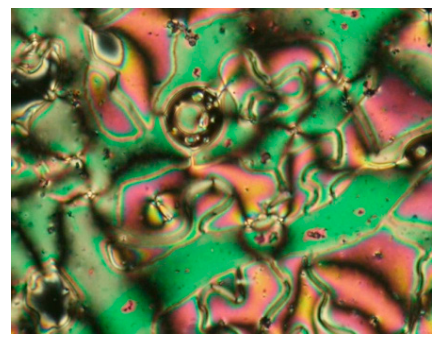

(a)

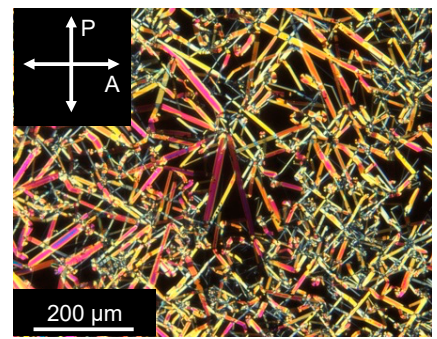

(b)

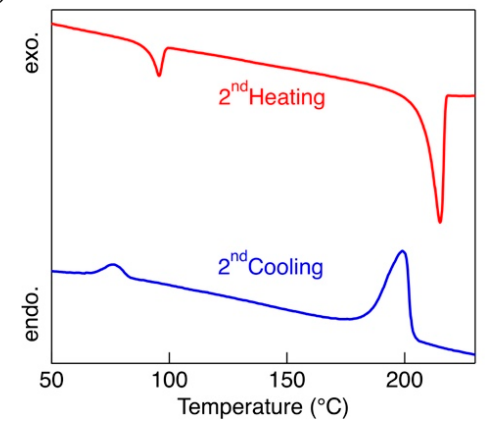

(c)

Figure 4. Polarizing optical micrographs of Au complexes $\mathbf{1}$ and $\mathbf{3 b}$ under crossed polarizers: (a) $\mathbf{1}$ at $78^{\circ} \mathrm{C}$ in the 1 st cooling process ( $\mathrm{N}$ phase); (b) $3 \mathbf{b}$ at $200^{\circ} \mathrm{C}$ in the 2 nd cooling process (SmA phase). White arrows show the direction of polarizers. (c) Differential scanning calorimetry (DSC) thermograms of complexes $3 \mathbf{b}$. Scanning rate: $2.0^{\circ} \mathrm{C} \mathrm{min}^{-1}$. 
Table 2. Phase transition behavior of Au complexes.

\begin{tabular}{|c|c|c|}
\hline Complex & & Sequences $T\left({ }^{\circ} \mathrm{C}\right)\left[\Delta H\left(\mathrm{~kJ} \mathrm{~mol}^{-1}\right)\right]$ \\
\hline 1 & $\begin{array}{l}\text { heating } \\
\text { cooling }\end{array}$ & $\begin{array}{c}\text { Cr } 89[7] \text { N } 93[0.2] \mathrm{I} \\
\text { Cr } 70[-6] \text { N } 94[-0.3] \mathrm{I}\end{array}$ \\
\hline $2 a$ & $\begin{array}{l}\text { heating } \\
\text { cooling }\end{array}$ & $\begin{array}{l}\text { Cr } 293 \text { I } \\
\text { Cr } 277 \text { I }\end{array}$ \\
\hline $2 b$ & $\begin{array}{l}\text { heating } \\
\text { cooling }\end{array}$ & $\begin{array}{c}\mathrm{Cr}_{1} 78[1] \mathrm{Cr}_{2} 132[3.4] \mathrm{Cr}_{3} 135[18] \mathrm{I} \\
\mathrm{Cr}_{1} 78[-1.2] \mathrm{Cr}_{2} 117[-23] \mathrm{I}\end{array}$ \\
\hline $3 a$ & $\begin{array}{l}\text { heating } \\
\text { cooling }\end{array}$ & $\begin{array}{c}\mathrm{Cr}_{1} 70[5.6] \mathrm{Cr}_{2} 187[3.8] \mathrm{Cr}_{3} 189[5.6] \mathrm{I} \\
\mathrm{Cr}_{1} 40[-5.2] \mathrm{Cr}_{2} 182[-17] \mathrm{I}\end{array}$ \\
\hline $3 b$ & $\begin{array}{l}\text { heating } \\
\text { cooling }\end{array}$ & $\begin{array}{c}\mathrm{Cr}_{1} \text { 91 [4.7] } \mathrm{Cr}_{2} 207 \text { [29] I } \\
\mathrm{Cr}_{1} 82[-2.9] \mathrm{Cr}_{2} 190 \mathrm{SmA} 203[-23] \mathrm{I}\end{array}$ \\
\hline
\end{tabular}

Abbreviations: Cr, crystalline; SmA, smectic A; N, nematic; I, isotropic.

Complex $\mathbf{3 b}$, in which the phenyl acetylide ligand was introduced to complex 2 to enlarge the aspect ratio of the mesogenic core, exhibited a monotropic Sm phase. Conversely, 3a did not show liquid crystallinity. This indicates that incorporation of two hexyloxy chains in the benzimidazole unit is important to decrease the crystallinity in order to obtain liquid crystallinity. The exothermic peak corresponding to the phase transition from an isotropic (I) phase to Sm phase was not observed for $\mathbf{3 b}$ in the DSC thermogram; moreover, the characteristic X-ray diffraction of the Sm phase could not be observed. As shown in Figure 4c, the endo- and exothermic peaks for Sm-to-I phase transitions are broad for this complex. In addition, the temperature range of the Sm phase is narrow. Therefore, signals indicating the existence of the Sm phase could not be observed with DSC and X-ray diffraction measurements. However, batonnet texture, which is typical for SmA or SmC phases, was observed at $200{ }^{\circ} \mathrm{C}$ with POM (Figure $4 \mathrm{~b}$ and Figure S5), and the material exhibited fluidity upon application of shear stress at this temperature. In addition, we identified the $\mathrm{Sm}$ phase by investigating the extinction angle: The POM image shows a dark area or line where mesogenic molecules align parallel to the polarizers of POM. As a result, the POM image of the batonnet texture with the growth direction parallel to the direction of polarizers became dark. When the batonnet growth direction is parallel to the normal direction of smectic layers, the molecular alignment in each layer is along the normal direction of smectic layers. This clearly means that complex 3a possesses a SmA LC phase. From the above arguments, we conclude that both liquid crystallinity and high thermal stability can be achieved by introducing both NHC and acetylide ligands to the $\mathrm{Au}(\mathrm{I})$ complexes.

\subsection{Photophysical Properties}

UV-vis absorption and photoluminescence spectra of Au complexes in solution $\left(\mathrm{CH}_{2} \mathrm{Cl}_{2}\right)$ are shown in Figure 5. All complexes exhibit an absorption band in the UV region, but no bands appear in the visible region, confirming complete transparency, which is a favorable property for luminescent materials. The molar extinction coefficients of all complexes at the absorption maxima $\left(\lambda_{\max }{ }^{\text {abs }}\right)$ were $\sim 10^{4} \mathrm{~L} \mathrm{~mol}^{-1} \mathrm{~cm}^{-1}$. This absorption band can be attributed to a ligand-based $\pi-\pi^{*}$ transition.

Complexes $\mathbf{2 a}$ and $\mathbf{2 b}$ displayed different $\lambda_{\max }{ }^{\text {abs }}\left(\lambda_{\max }{ }^{\text {abs }}=288 \mathrm{~nm}\right.$ for $2 \mathbf{a}$ and $306 \mathrm{~nm}$ for $\left.\mathbf{2 b}\right)$ and band shapes. The red shift of $\lambda_{\max }{ }^{\text {abs }}$ for $\mathbf{2} \mathbf{b}$ may be due to electron donation from the hexyloxy groups introduced to the phenyl ring of the benzimidazole unit. The absorption spectrum of $3 \mathbf{a}$ appears to be the sum of the spectra for complexes $\mathbf{1}$ and $\mathbf{2 a}$. Two absorption bands are observed for $\mathbf{3 b}$ at $\sim 300 \mathrm{~nm}$ and $\sim 320 \mathrm{~nm}$; both absorption bands correspond with those of $\mathbf{1}$ and $\mathbf{2 b}$, respectively. 


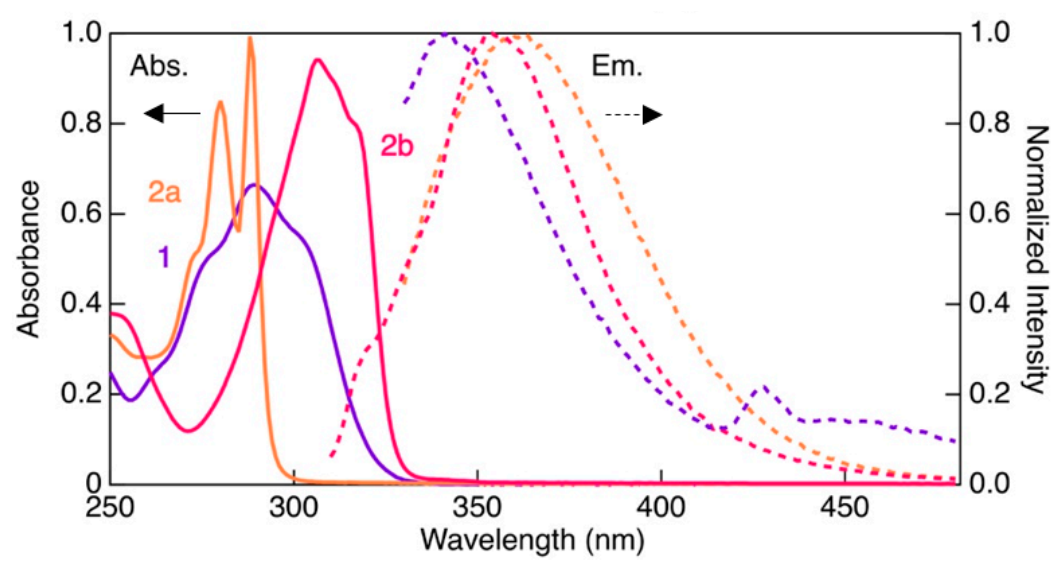

(a)

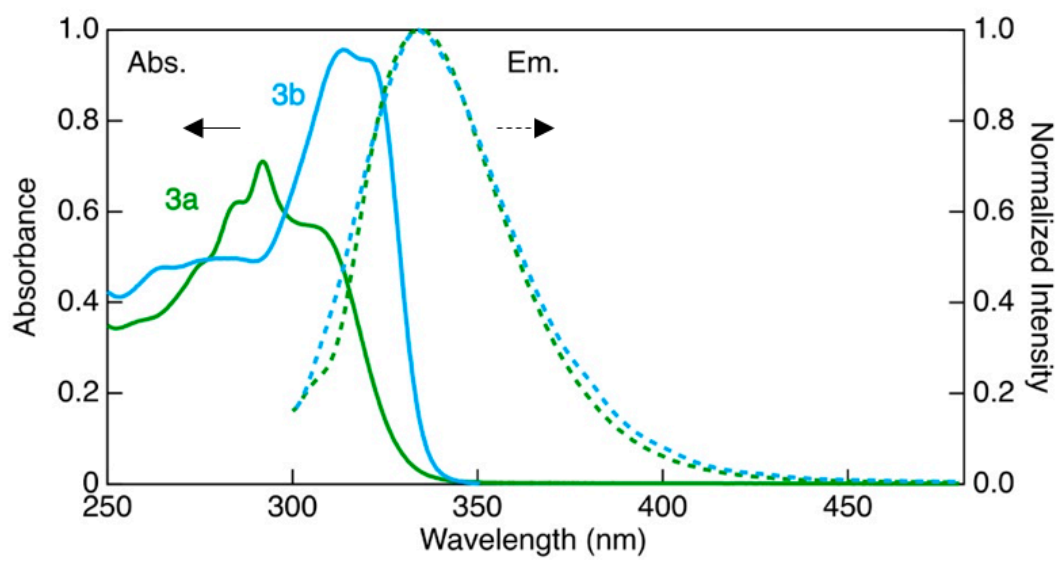

(b)

Figure 5. Photophysical properties of Au complexes in dilute $\mathrm{CH}_{2} \mathrm{Cl}_{2}$ solutions: solid line, absorption spectra; dashed line, photoluminescence spectra. (a) Complexes $\mathbf{1}$ and $\mathbf{2}$ and (b) complexes 3. UV-vis absorption concentrations: [1] $=2.7 \times 10^{-5} \mathrm{~mol} \mathrm{~L}^{-1},[2 \mathrm{a}]=4.5 \times 10^{-5} \mathrm{~mol} \mathrm{~L}^{-1}$, $[\mathbf{2 b}]=4.0 \times 10^{-5} \mathrm{~mol} \mathrm{~L}^{-1},[3 \mathbf{a}]=2.0 \times 10^{-5} \mathrm{~mol} \mathrm{~L}^{-1},[3 \mathbf{b}]=2.0 \times 10^{-5} \mathrm{~mol} \mathrm{~L}^{-1}$. Luminescence concentrations: $[\mathbf{1}]=2.7 \times 10^{-6} \mathrm{~mol} \mathrm{~L}^{-1},[\mathbf{2 a}]=4.5 \times 10^{-6} \mathrm{~mol} \mathrm{~L}^{-1},[\mathbf{2 b}]=4.0 \times 10^{-6} \mathrm{~mol} \mathrm{~L}^{-1}$, $[3 \mathbf{a}]=2.0 \times 10^{-6} \mathrm{~mol} \mathrm{~L}^{-1},[3 \mathbf{b}]=2.0 \times 10^{-6} \mathrm{~mol} \mathrm{~L}^{-1}$. The excitation wavelength of the luminescence spectra $\left(\lambda_{\text {ex }}\right)$ was $280 \mathrm{~nm}$.

Next, we investigated the photoluminescence properties of complexes in dilute solutions $\left(10^{-6} \mathrm{~mol} \mathrm{~L}^{-1}\right)$. New complexes $\mathbf{3 a}$ and $\mathbf{3 b}$ exhibit the same luminescence band at $\sim 340 \mathrm{~nm}$, which is the same wavelength observed for complex $\mathbf{1}$. Complexes $\mathbf{2} \mathbf{a}$ and $\mathbf{2} \mathbf{b}$ both displayed the same luminescence at longer wavelength $(\sim 360 \mathrm{~nm})$, which indicates that introduction of the long alkoxy tails on the phenyl ring of $\mathbf{2} \mathbf{b}$ does not affect the electronic structure of its luminescent-excited state. The emissions observed for all complexes in the UV region in dilute solution are likely from metal-to-ligand charge transfer (MLCT) or ligand-based $\pi-\pi^{*}$ transitions of the monomer (i.e., emission from the isolated molecule and not aggregates) [31,32]. Furthermore, comparison of the luminescence spectra of complexes $\mathbf{1}$ and $\mathbf{3}$ indicate that the luminescent-excited state of complexes $\mathbf{3 a}$ and $\mathbf{3 b}$ are localized on the phenylacetylene moiety.

Figure 6a shows the photoluminescence spectra of the complexes as crystals. The gold(I) complexes exhibited intense photoluminescence in the solid state, see Figure $6 \mathrm{~b}$; complex $\mathbf{1}$ in particular possesses a very large quantum yield [23]. The luminescence bands from the crystals were significantly red-shifted compared with those of dilute solutions, suggesting that luminescence arises from a lower energy level excited state, such as the triplet state, when in the solid state. The luminescence spectra from 
crystals of complexes $\mathbf{1}, \mathbf{3 a}$, and $\mathbf{3 b}$ were nearly the same, with a band appearing around $450 \mathrm{~nm}$ with a vibronic structure.

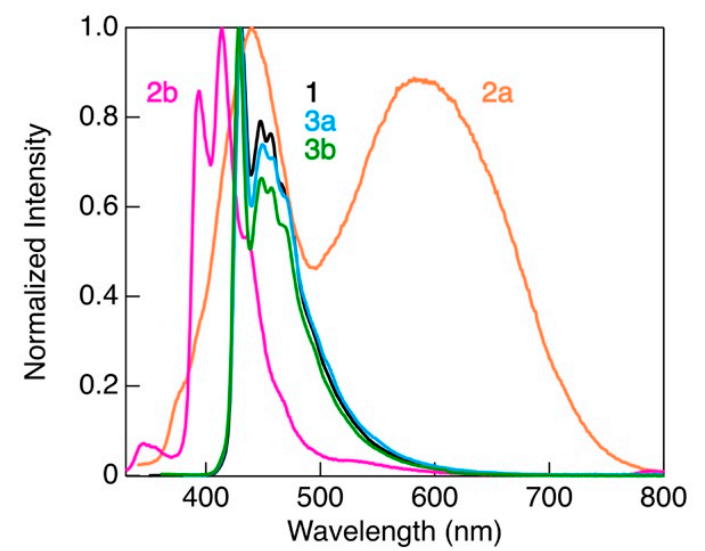

(a)

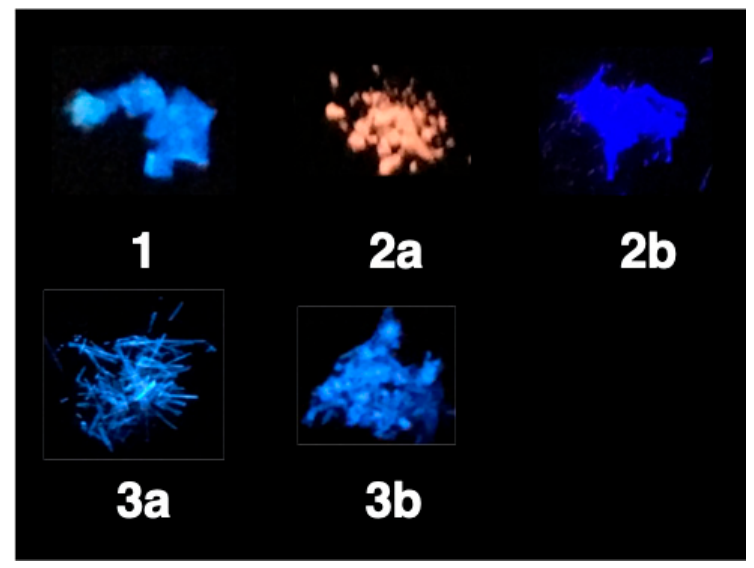

(b)

Figure 6. Photoluminescence spectra of $\mathrm{Au}$ complexes as crystals at room temperature in air. (a), luminescence spectra (black: 1, $\lambda_{\mathrm{ex}}=290 \mathrm{~nm}$; red: $2 \mathrm{a}, \lambda_{\mathrm{ex}}=266 \mathrm{~nm}$; orange: $\mathbf{2 b}, \lambda_{\mathrm{ex}}=274$ nm; blue: $3 \mathbf{a}, \lambda_{\mathrm{ex}}=328 \mathrm{~nm}$; green: $\mathbf{3 b}, \lambda_{\mathrm{ex}}=335 \mathrm{~nm}$ ). (b), Photographs of crystals taken under UV irradiation at $365 \mathrm{~nm}$.

Complexes $\mathbf{2 a}$ and $\mathbf{2 b}$ showed luminescence bands at different wavelength from those of the other complexes in the solid state. As we previously reported, although the luminescence behavior of complexes $\mathbf{2} \mathbf{a}$ and $\mathbf{2} \mathbf{b}$ was nearly the same in dilute solution, significant differences were observed in the luminescence spectra of the crystals [14]. The complex 2a crystals produce two luminescent bands at $430 \mathrm{~nm}$ and $\sim 600 \mathrm{~nm}$; by contrast, crystals of $\mathbf{2 b}$ exhibit only one luminescence band at a shorter wavelength. Consequently, crystals of $\mathbf{2} \mathbf{a}$ and $\mathbf{2} \mathbf{b}$ showed distinct luminescence colors; orange and blue photoluminescence could be observed with the naked eye upon UV irradiation of the $2 \mathbf{a}$ and $\mathbf{2 b}$ crystals at $365 \mathrm{~nm}$, respectively, see Figure $6 \mathbf{b}$. Moreover, only the crystals of $\mathbf{2 b}$ exhibited a very small luminescence band in the UV region at $350 \mathrm{~nm}$. The spectral shape and wavelengths of the luminescence bands in the UV region observed from crystals of $\mathbf{2} \mathbf{b}$ were identical to those observed in dilute solution, and thus, we can assign this small luminescence band at $350 \mathrm{~nm}$ to fluorescence emitted from the monomeric-excited state [14]. As we reported, the luminescence band at $600 \mathrm{~nm}$ observed only for $\mathbf{2 a}$ is due to the intermolecular $\mathrm{Au}-\mathrm{Au}$ interaction, and are assigned to a metal-metal-to-ligand charge transfer (MMLCT) band [14].

The photoluminescence lifetime $(\tau)$ of the crystals was measured for each complex. The decay profiles are shown in Figure S7, and the results are summarized in Table 3. The decay profiles were fitted with a single-exponential function. Single-exponential decays were observed for new complexes $\mathbf{3 a}$ and $\mathbf{3 b}$ with a time scale longer than $30 \mu \mathrm{s}$; additionally, those for the remaining complexes are also on the order of the $\mu$ s timescale. These results indicate that the observed photoluminescence from the crystals is phosphorescence.

As displayed in Table 3, all complexes exhibited phosphorescence with considerably high quantum yield $(\Phi=0.12-0.50)$ at room temperature under ambient conditions. This strong room temperature phosphorescence in air is explained by the combination of the following three points: (1) crystallization-induced phosphorescence, as previously reported by Tang et al., occurs when densely packed crystals prevent penetration of molecular oxygen from quenching the triplet excited state [33]; (2) the heavy atom, Au, exists in the densely packed lattice, which induces both internal and external heavy atom effects simultaneously, and enhances the rate of both the spin-forbidden singlet-triplet intersystem crossing and triplet-singlet radiative transition; and (3) internal motions such as vibration and rotation of molecules, which result in non-radiative deactivation of excited states, is effectively restricted by intermolecular interactions in the densely packed crystals. 
Table 3. Photophysical parameters for gold complexes as crystals at room temperature.

\begin{tabular}{|c|c|c|c|c|c|}
\hline Complex & $\lambda_{\max } \operatorname{lum}[\mathrm{nm}]$ & $\tau[\mu \mathrm{s}]$ & $\Phi$ & $k_{\mathrm{r}}\left[\mathrm{s}^{-1}\right]$ & $k_{\mathrm{nr}}\left[\mathrm{s}^{-1}\right]$ \\
\hline 1 & 431 & 52 & 0.50 & $9.6 \times 10^{3}$ & $9.6 \times 10^{3}$ \\
\hline \multirow{2}{*}{$2 a$} & 440 & 0.34 & 0.05 & $1.4 \times 10^{5}$ & $2.8 \times 10^{6}$ \\
\hline & 590 & 5.4 & 0.11 & $2.0 \times 10^{4}$ & $1.7 \times 10^{5}$ \\
\hline $2 b$ & 414 & 12 & 0.12 & $1.0 \times 10^{4}$ & $7.6 \times 10^{4}$ \\
\hline $3 a$ & 430 & 32 & 0.43 & $1.3 \times 10^{4}$ & $1.8 \times 10^{4}$ \\
\hline $3 b$ & 429 & 36 & 0.33 & $9.3 \times 10^{3}$ & $1.9 \times 10^{4}$ \\
\hline
\end{tabular}

Abbreviations: $\lambda_{\max }{ }^{\text {lum }}$, maximum wavelength for emission; $\tau$, lifetime; $k_{\mathrm{r}}$, rate constant for the radiative transition estimated by $\Phi / \tau ; k_{\mathrm{nr}}$, rate constant for the non-radiative deactivation estimated by $(1-\Phi) / \tau$.

Compared with complexes $\mathbf{2}$, complexes 3 showed larger $\Phi$ for room temperature phosphorescence. As mentioned above, the excited state for luminescence in complexes 3 mainly involves the phenylacetylide ligand in dilute solutions. Furthermore, complexes 3 exhibited luminescence bands with the same vibronic structure and at the same wavelength as complex 1, suggesting that the luminescent-excited state of $\mathbf{3}$ still involves the phenylacetylide ligand; complex $\mathbf{1}$ displayed high room-temperature phosphorescence $\Phi$, even for the crystals in the solid state. This suggests that the room temperature phosphorescence $\Phi$ could be improved by introducing a phenylacetylide ligand. As summarized in Table 3, except for the band at $440 \mathrm{~nm}$ in complex 2a, all complexes possess almost the same rate constant for the radiative transition, $\mathrm{k}_{\mathrm{r}}$, for the crystals: $\sim 1 \times 10^{4} \mathrm{~s}^{-1}$. However, the rate constants for non-radiative deactivation, $\mathrm{k}_{\mathrm{nr}}$, are significantly larger for complexes $\mathbf{2 a}$ and $\mathbf{2 b}$ $\left(\sim 8 \times 10^{4}\right.$ to $\left.3 \times 10^{6} \mathrm{~s}^{-1}\right)$ compared with those of the other complexes $\left(\sim 1 \times 10^{4}\right.$ to $\left.2 \times 10^{4} \mathrm{~s}^{-1}\right)$; ratios of both rate constants, $\mathrm{k}_{\mathrm{nr}} / \mathrm{k}_{\mathrm{r}}$, are 8-20 for complexes 2 and 1-2 for the others. Namely, the excited state involving the NHC ligand follows a fast non-radiative deactivation pathway. By introducing the phenylacetylide ligand, the luminescent-excited state is localized on the phenylacetylide ligand. As a result, the non-radiative deactivation process could be suppressed, leading to improved room temperature phosphorescence.

\section{Conclusions}

In conclusion, we synthesized gold(I) complexes $\mathbf{3 a}$ and $\mathbf{3 b}$ that exhibited both high thermochemical stabilities and intense room temperature phosphorescence $(\Phi=0.43$ for $\mathbf{3 a}, 0.33$ for $\mathbf{3 b})$ as crystals under ambient conditions, merely by the incorporation of NHC and acetylide ligands. We experimentally demonstrated that the NHC ligand was essential for increasing the thermochemical stabilities, and that the excited state localized on the NHC ligand produces fast non-radiative decay. On the other hand, incorporation of both NHC and phenylacetylide ligands could suppress the non-radiative decay process. This indicates that the electron distribution in the excited state is localized not on the NHC ligand, but on the phenylacetylide ligand. Therefore, complexes containing phenylacetylide ligands exhibited higher $\Phi$. Of particular interest here are the results that provide us with guidelines toward the design of luminescent gold(I) complexes. Namely, we can design molecular functionalities with properties such as thermochemical stability and high phosphorescence quantum yield separately, and then incorporate these different rationally designed ligands in gold(I) complexes. Furthermore, we found that the modification of the length of alkoxy chains at each ligand enables us to generate liquid crystallinity while maintaining both the thermochemical stability and the phosphorescence quantum yield. We believe that the rational design of each ligand could allow for the desired properties of materials on demand, opening up the development of luminescent materials for next-generation photonic applications.

Supplementary Materials: The following are available online at http://www.mdpi.com/2073-4352/9/5/227/s1. Figure S1: NMR spectrum of gold complex $3 \mathbf{a}$ in $\mathrm{CDCl}_{3}$, Figure S2: NMR spectrum of gold complex $3 \mathbf{b}$ in $\mathrm{CDCl}_{3}$, Table S1: Crystallographic data for gold complexes, Figure S3: Packing structures of gold complexes $\mathbf{3 a}$ and $\mathbf{3 b}$, Figure S4: TG/DTA thermograms of complexes 1 and $\mathbf{2}$ in air, Figure S5: A POM image of the complex $\mathbf{3 b}$ observed 
at $200{ }^{\circ} \mathrm{C}$ with higher magnification, Figure S6: DSC thermograms of complexes 3a, Figure S7: Photoluminescence decay profiles of crystal of complex $\mathbf{3 a}$ and $\mathbf{3 b}$.

Author Contributions: conceptualization, O.T.; methodology and investigation, Y.K, S.N., K.S., A.S., G.P.; writing—original draft preparation, Y.K.; writing—review and editing, P.G. K.H., O.T.; project administration, O.T.

Funding: This research was supported by JSPS KAKENHI (18K05265, 18H03764, and 19K21131), JICA Collaboration Kick-starter Program (RU and IITH), Japan-Egypt Research Cooperative Program (JSPS and MOSR-STDF), JST Matching Planner Program (VP29117941122), Research Program from Ritsumeikan Global Innovation Research Organization (R-GIRO), and Cooperative Research Program of the Network Joint Research Center for Materials and Devices (Tokyo Institute of Technology).

Conflicts of Interest: The authors declare no conflict of interest.

\section{References}

1. Lim, X.Z. The nanolight revolution is coming. Nature 2016, 531, 26-28. [CrossRef]

2. Song, J.; Li, J.; Li, X.; Xu, L.; Dong, Y.; Zeng, H. Quantum dot light-emitting diodes based on inorganic perovskite cesium lead halides $\left(\mathrm{CsPbX}_{3}\right)$. Adv. Mater. 2015, 27, 7162-7167. [CrossRef]

3. Feng, G.; Liu, B. Aggregation-induced emission (AIE) dots: Emerging theranostic nanolights. Acc. Chem. Res. 2018, 51, 1404-1414. [CrossRef] [PubMed]

4. Jiang, K.; Wang, Y.; Cai, C.; Lin, H. Activating room temperature long afterglow of carbon dots via covalent fixation. Chem. Mater. 2017, 29, 4866-4873. [CrossRef]

5. Liu, J.; Wang, N.; Yu, Y.; Yan, Y.; Zhang, H.; Li, J.; Yu, J. Carbon dots in zeolites: A new class of thermally activated delayed fluorescence materials with ultralong lifetimes. Sci. Adv. 2017, 3, e1603171. [CrossRef]

6. Hong, Y.; Lam, J.W.Y.; Tang, B.Z. Aggregation-induced emission. Chem. Soc. Rev. 2011, 40, 5361-5388. [CrossRef] [PubMed]

7. Dang, D.; Qiu, Z.; Han, T.; Liu, Y.; Chen, M.; Kwok, R.T.K.; Lam, J.W.Y.; Tang, B.Z. 1 + 1 >> 2: Dramatically enhancing the emission efficiency of TPE-based AIEgens but keeping their emission color through tailored alkyl linkages. Adv. Funct. Mater. 2018, 28, 1707210. [CrossRef]

8. Lintang, H.O.; Kinbara, K.; Tanaka, K.; Yamashita, T.; Aida, T. Self-repair of a one-dimensional molecular assembly in mesoporous silica by a nanoscopic template effect. Angew. Chem. Int. Ed. 2010, 49, 4241-4245. [CrossRef]

9. Mocanu, A.S.; Amela-Cortes, M.; Molard, Y.; Cîrcu, V.; Cordier, S. Liquid crystal properties resulting from synergetic effects between non-mesogenic organic molecules and a one nanometre sized octahedral transition metal cluster. Chem. Commun. 2011, 47, 2056-2058. [CrossRef]

10. Krikorian, M.; Liu, S.; Swager, T.M. Columnar liquid crystallinity and mechanochromism in cationic platinum (II) complexes. J. Am. Chem. Soc. 2014, 136, 2952-2955. [CrossRef]

11. Kawano, S.I.; Ishida, Y.; Tanaka, K. Columnar liquid-crystalline metallomacrocycles. J. Am. Chem. Soc. 2015, 137, 2295-2302. [CrossRef]

12. Concellón, A.; Marcos, M.; Romero, P.; Serrano, J.L.; Termine, R.; Golemme, A. Not only columns: High hole mobility in a discotic nematic mesophase formed by metal-containing porphyrin-core dendrimers. Angew. Chem. Int. Ed. 2017, 129, 1279-1283. [CrossRef]

13. Fujisawa, K.; Mitsuhashi, F.; Anukul, P.; Taneki, K.; Younis, O.; Tsutsumi, O. Photoluminescence behavior of liquid-crystalline gold(I) complexes with a siloxane group controlled by molecular aggregate structures in condensed phases. Polym. J. 2018, 50, 761-769. [CrossRef]

14. Sathyanarayana, A.; Nakamura, S.; Hisano, K.; Tsutsumi, O.; Srinivas, K.; Prabusankar, G. Controlling the solid-state luminescence of gold(I) N-heterocyclic carbene complexes through changes in the structure of molecular aggregates. Sci. China Chem. 2018, 61, 957-965. [CrossRef]

15. Preeyanuch, A.; Sugimoto, N.; Sakamoto, K.; Rokusha, Y.; Taneki, K.; Fujisawa, K.; Tsutsumi, O. Effects of aromatic core and flexible terminal chain structures on the properties of luminous liquid-crystalline gold(I) complexes for functional materials. Mol. Cryst. Liq. Cryst. 2018, 662, 176-187.

16. Yamada, S.; Rokusha, Y.; Kawano, R.; Fujisawa, K.; Tsutsumi, O. Mesogenic gold complexes showing aggregation-induced enhancement of phosphorescence in both crystalline and liquid-crystalline phases. Faraday Discuss. 2017, 196, 269-283. [CrossRef] [PubMed]

17. Yamada, S.; Yamaguchi, S.; Tsutsumi, O. Electron-density distribution tuning for enhanced thermal stability of luminescent gold complexes. J. Mater. Chem. C 2017, 5, 7977-7984. [CrossRef] 
18. Kawano, R.; Younis, O.; Ando, A.; Rokusha, Y.; Yamada, S.; Tsutsumi, O. Photoluminescence from Au(I) complexes exhibiting color sensitivity to the structure of the molecular aggregates. Chem. Lett. 2016, 45, 66-68. [CrossRef]

19. Younis, O.; Rokusha, Y.; Sugimoto, N.; Fujisawa, K.; Yamada, S.; Tsutsumi, O. Effects of molecular structure and aggregated structure on photoluminescence properties of liquid-crystalline gold(I) complexes with various aromatic rings. Mol. Cryst. Liq. Cryst. 2015, 617, 21-31. [CrossRef]

20. Fujisawa, K.; Yamada, S.; Yanagi, Y.; Yoshioka, Y.; Kiyohara, A.; Tsutsumi, O. Tuning the photoluminescence of condensed-phase cyclic trinuclear $\mathrm{Au}(\mathrm{I})$ complexes through control of their aggregated structures by external stimuli. Sci. Rep. 2015, 5, 7934. [CrossRef]

21. Sugimoto, N.; Tamai, S.; Fujisawa, K.; Tsutsumi, O. Photoluminescent gold(I) complex with biphenyl acetylene ligand showing stable nematic liquid-crystalline phase. Mol. Cryst. Liq. Cryst. 2014, 601, 97-106. [CrossRef]

22. Fujisawa, K.; Okuda, Y.; Izumi, Y.; Nagamatsu, A.; Rokusha, Y.; Sadaike, Y.; Tsutsumi, O. Reversible thermal-mode control of luminescence from liquid-crystalline gold(I) complexes. J. Mater. Chem. C 2014, 2 , 3549-3555. [CrossRef]

23. Fujisawa, K.; Kawakami, N.; Onishi, Y.; Izumi, Y.; Tamai, S.; Sugimoto, N.; Tsutsumi, O. Photoluminescent properties of liquid crystalline gold(I) isocyanide complexes with a rod-like molecular structure. J. Mater. Chem. C 2013, 1, 5359-5366. [CrossRef]

24. Schmidbaur, $\mathrm{H}$. The aurophilicity phenomenon: A decade of experimental findings, theoretical concepts and emerging applications. Gold Bull. 2000, 33, 3-10. [CrossRef]

25. Ong, C.W.; Liao, S.-C.; Chang, T.H.; Hsu, H.-F. In situ synthesis of hexakis(alkoxy)diquinoxalino[2,3-a:2' ${ }^{\prime} 3^{\prime}-$ c]phenazines: Mesogenic phase transition of the electron-deficient discotic compounds. J. Org. Chem. 2004, 69, 3181-3185. [CrossRef]

26. Wang, H.M.J.; Chen, C.Y.L.; Lin, I.J.B. Synthesis, structure, and spectroscopic properties of gold(I)-carbene complexes. Organometallics 1999, 18, 1216-1223. [CrossRef]

27. Sheldrick, G.M. SHELXS-2014, Program for crystal structure solution; University of Göttingen: Göttingen, Germany, 2014.

28. Sheldrick, G.M. A short history of SHELX. Acta Crystallogr. A 2008, 64, 112-122. [CrossRef] [PubMed]

29. Schmidbaur, H.; Schier, A. Aurophilic interactions as a subject of current research: An update. Chem. Soc. Rev. 2012, 41, 370-412. [CrossRef]

30. Suezawa, H.; Yoshida, T.; Umezawa, Y.; Tsuboyama, S.; Nishio, M. CH/ $\pi$ interactions implicated in the crystal structure of transition metal compounds - A database study. Eur. J. Inorg. Chem. 2002, 3148-3155. [CrossRef]

31. Yam, V.W.-W.; Au, V.K.-M.; Leung, S.Y.-L. Light-emitting self-assembled materials based on $\mathrm{d}^{8}$ and $\mathrm{d}^{10}$ transition metal complexes. Chem. Rev. 2015, 115, 7589-7728. [CrossRef]

32. Tiekink, E.R.T.; Kang, J.-G. Luminescence properties of phosphinegold(I) halides and thiolates. Coord. Chem. Rev. 2009, 253, 1627-1648. [CrossRef]

33. Mei, J.; Leung, N.L.C.; Kwok, R.T.K.; Lam, J.W.Y.; Tang, B.Z. Aggregation-induced emission: Together we shine, united we soar! Chem. Rev. 2015, 115, 11718-11940. [CrossRef] [PubMed]

(C) 2019 by the authors. Licensee MDPI, Basel, Switzerland. This article is an open access article distributed under the terms and conditions of the Creative Commons Attribution (CC BY) license (http://creativecommons.org/licenses/by/4.0/). 